\title{
Optimization of Acid Hydrolysis of Myricetin-3-O-rhamnoside Using Response Surface Methodology
}

\author{
Tatiana C. Tolosa, ${ }^{a}$ Hervé Rogez, ${ }^{a}$ Evaldo M. Silva ${ }^{b}$ and Jesus N. S. Souza ${ }^{*, a}$ \\ ${ }^{a}$ Centro de Valorização de Compostos Bioativos da Amazônia (CVACBA), \\ Universidade Federal do Pará, 66075-970 Belém-PA, Brazil \\ ${ }^{b}$ Faculdade de Engenharia de Pesca, Instituto de Estudos Costeiros, Universidade Federal do Pará, \\ 68370-000 Bragança-PA, Brazil
}

\begin{abstract}
This study aimed to optimize the acid hydrolysis of glycosylated flavonols, to apply the optimum conditions for hydrolyzing Inga edulis extract (IEE), rich in glycosylated flavonols, and evaluating its impact on the antioxidant capacity. To evaluate the influence of three independent variables on the aglycone obtained after the reaction, the response surface methodology was applied using myricetin-3-O-rhamnoside (M3R) as a pure compound. The phenolic compound profile and antioxidant capacity were determined by high-performance liquid chromatography (HPLC) and the Trolox-equivalent antioxidant capacity (TEAC) assay, respectively. The maximum content of the aglycone myricetin (81.15\%) occurred with $2.5 \mathrm{M} \mathrm{HCl}$ at $75^{\circ} \mathrm{C}$ for $60 \mathrm{~min}$. Under these conditions, the IEE produced the aglycones myricetin, quercetin and cyanidin. The TEAC values of the M3R samples and IEE before and after acid hydrolysis did not show significant differences $(p>0.05)$. These results suggest that the hydrolytic process is effective to produce aglycone flavonoids from leaf extracts of I. edulis, and probably for other plant extracts rich in M3R.
\end{abstract}

Keywords: phenolic aglycone, antioxidant capacity, hydrolytic process, Inga edulis

\section{Introduction}

In food preservation, oxidative processes are the main cause of quality loss. Faced with this problem, food manufacturers add antioxidants to prevent the formation of oxidation products. The interest in finding natural antioxidants for use in foods, cosmetics and pharmaceuticals has increased considerably, with the aim of substituting the synthetic antioxidants, which have recently been reported to be potentially dangerous to human health. ${ }^{1-3}$

Natural antioxidants are formed by a large variety of compounds, including phenolics, carotenoids, ascorbic acid and tocopherols. ${ }^{4}$ Among the phenolic compounds, flavonoids have been shown to be potent antioxidants in foods preventing oxidative stress in aerobic conditions, which is defined as an imbalance in reactive oxygen species. ${ }^{4-6}$

Flavonoids are polyphenolic compounds with two aromatic rings connected by a three-carbon bridge, $\mathrm{C}_{6}-\mathrm{C}_{3}-\mathrm{C}_{6}$. The basic flavonoid skeleton can have numerous substituents. Sugars are very common, with the majority of flavonoids existing naturally as glycosides, which increases

*e-mail: jsouza@ufpa.br their water solubility. ${ }^{7}$ Inga edulis Mart. (Leguminosae) is an Amazon plant that it can actively fix nitrogen. ${ }^{8}$ The leaves of this plant are rich in polyphenolic compounds and myricetin-3-O-rhamnoside (M3R) is one of the major phenolics of this plant and is responsible for $88.6 \%$ of the flavonol family concentration. ${ }^{9,10}$

Recent efforts have been concentrated on the structural modification of phenolic compounds, by chemical or enzymatic catalysis, to alter their properties and expand the range of their application to more diverse systems, e.g. nanoencapsulation, adsorption onto macroporous resins. ${ }^{11-15}$ Lipophilic derivatives of phenolic compounds generally maintain their antioxidant activity and, in some cases, exhibit novel bioactivities that are not found in the original phenolic compounds. ${ }^{16-18}$

To potentiate the use of polyphenolic antioxidants from natural sources, in addition to the extraction and purification of these compounds, it is necessary to use a process that separates the aglycones (more apolar) from the carbohydrates, such as acid hydrolysis. Acid hydrolysis is a chemical reaction in which an organic molecule undergoes decomposition caused by water, where the acid acts as a catalyst. ${ }^{17,19}$ 
Thus, the aims of this paper are to $(i)$ optimize the hydrolysis of a flavonol, M3R, by response surface methodology (RSM) and determine the experimental conditions (acid concentration, temperature and reaction time) that maximize the aglycone yield; (ii) evaluate the applicability of the optimized conditions on a partially purified extract of Inga edulis and (iii) evaluate the effect of hydrolysis on the antioxidant capacity of the extract by the Trolox-equivalent antioxidant capacity (TEAC).

\section{Experimental}

\section{Preparation of flavonol standard solutions}

Myricetin, cyanidin, quercetin and M3R (Sigma, St. Louis, MO, USA) were of HPLC grade. Stock solutions of standards were prepared in methanol at a concentration of $1000 \mu \mathrm{g} \mathrm{mL}^{-1}$ and stored under a nitrogen atmosphere at $-20{ }^{\circ} \mathrm{C}$.

\section{Extract of Inga edulis leaves}

The extract of $I$. edulis leaf was kindly donated by Amazon Dreams S/A, a company located in Belém (Pará, Brazil) that manufactures purified plant extracts. The extract was obtained after applying the appropriate techniques for the extraction and purification (adsorption/desorption) of phenolic compounds using synthetic macroporous resin..$^{20,21}$

\section{Preliminary study}

A preliminary study was conducted to determine the impact that the type and amount of alcohol present in the reaction medium have on the percentage of aglycone obtained. Two alcohols were chosen, methanol and ethanol; the former is frequently used for hydrolysis reactions, and the second is suitable for food-grade use. The aglycone yield was determined after the hydrolysis of M3R $\left(25 \mu \mathrm{g} \mathrm{mL}^{-1}\right)$ under the same conditions of temperature $\left(75^{\circ} \mathrm{C}\right), \mathrm{HCl}$ concentration $(2.5 \mathrm{M})$, time $(120 \mathrm{~min})$, and alcohol:water ratio $(60: 40, \mathrm{v} / \mathrm{v})$. After defining the type of alcohol, a second experiment was carried out with different percentages of alcohol $(0-80 \%, \mathrm{v} / \mathrm{v})$ to determine the optimal percentage to obtain the highest concentration of aglycone.

\section{Experimental design}

The optimization was done through RSM, using a central composite rotational design with six replicates at the central point. The influences of three variables, hydrochloric acid concentration ( $\mathrm{HCl})$, hydrolysis time (time) and temperature $(\mathrm{T})$, were evaluated on the dependent variable, myricetin yield (\%). The experimental domain used in this work is presented in Table 1.

The experimental design runs were conducted in tubes with a screw cap and Teflon septum. In all runs, $25 \mu \mathrm{g} \mathrm{mL}^{-1}$ of M3R was used for the hydrolysis in alcoholic medium and was acidified with $\mathrm{HCl}$ under heating in a water bath. A multiple linear regression analysis was performed on the yield data. Mathematical modeling of data was done using a second-order polynomial model (equation 1):

$$
\begin{aligned}
& \mathrm{Y}(\%)=\beta_{0}+\beta_{\mathrm{H}} \mathrm{H}+\beta_{\mathrm{T}} \mathrm{T}+\beta_{\mathrm{t}} \mathrm{t}+\beta_{\mathrm{H}} \mathrm{H}^{2}+\beta_{\mathrm{T}} \mathrm{T}^{2}+\beta_{\mathrm{t}} \mathrm{t}^{2}+ \\
& \beta_{\mathrm{HT}} \mathrm{HT}+\beta_{\mathrm{Ht}} \mathrm{Ht}+\beta_{\mathrm{Tt}} \mathrm{Tt}+\beta_{\mathrm{HT}} \mathrm{HTt}
\end{aligned}
$$

where $\mathrm{H}([\mathrm{HCl}]), \mathrm{T}$ (reaction temperature) and $\mathrm{t}$ (reaction time) are the independent variables affecting the response variable, $Y$ (yield, in percentage), and $\beta_{0}, \beta_{\mathrm{i}}(\mathrm{i}=\mathrm{H}, \mathrm{T}$ and t), $\beta_{\mathrm{ii}}$, and $\beta_{\mathrm{ij}}(\mathrm{j}=\mathrm{H}, \mathrm{T}$ and $\mathrm{t}$ ) are the coefficients for the intercept, linear, quadratic and interaction parameters, respectively.

\section{Determination of optimum conditions and model validation}

The choice of optimum conditions was performed according to the values of desirability (D). D values can vary from 0 to 1 and usually have a directly proportional relationship with the dependent variable in experiments that aim to maximize the product. ${ }^{22,23}$ Thus, the optimized conditions for the $\mathrm{HCl}$ concentration, temperature and reaction time would be those in which the $\mathrm{D}$ value corresponds to the maximization of the concentration of aglycones produced (reaction yield), i.e., $\mathrm{D}=1$.

Table 1. Coded and actual levels of the three independent variables

\begin{tabular}{lccccc}
\hline \multirow{2}{*}{ Variable } & \multicolumn{4}{c}{ Coded and original value of variable } \\
\cline { 2 - 6 } & -1.68 & -1 & 0 & +1 & +1.68 \\
\hline Hydrochloric acid concentration / M & 0.22 & 1.1 & 2.5 & 3.9 & 4.78 \\
Hydrolysis time / min & 22.2 & 60 & 120 & 180 & 217.8 \\
Reaction temperature $/{ }^{\circ} \mathrm{C}$ & 50.5 & 60 & 75 & 90 & 99.5 \\
\hline
\end{tabular}


For validation, hydrolysis was performed in triplicate under the optimum conditions. The values of the aglycone flavonol yield obtained experimentally were compared with those predicted by the model to verify the applicability of the empirical model. After validation, the optimized conditions for the hydrolysis of glycosylated flavonol were applied to the extract of I. edulis, a plant that contains a high concentration of M3R. The concentration of M3R was adjusted to the standard concentration, and the percentage of ethanol was the same as that used for the standards.

Evaluation of hydrolysis by high-performance liquid chromatography coupled to diode array detector (HPLC-DAD)

The HPLC system employed was a Shimadzu LC-10Avp (Tokyo, Japan) equipped with a diode array detector (SPD-M20A). The analysis was performed on a Gemini C18 reversed-phase column (3 $\mu$ m i.d., $150 \times 4.6 \mathrm{~mm}$; Phenomenex, Torrance, CA) maintained at $30{ }^{\circ} \mathrm{C}$. The methodology used to analyze the flavonols by HPLC was based on a previous study. ${ }^{9}$ The mobile phase for the elution of myricetin and M3R standards was composed of ultrapure water (solvent A) and acetonitrile (solvent B), both of which were acidified with $1 \%$ formic acid. The elution of standards was performed under a flow rate of $1 \mathrm{~mL} \mathrm{~min}-1$ with the following gradient: $25-35 \%$ $\mathrm{B}$ for $5 \mathrm{~min}, 35-25 \% \mathrm{~B}$ for $1 \mathrm{~min}$, and $25 \% \mathrm{~B}$ for $2 \mathrm{~min}$. The elution of the extract of $I$. edulis followed the elution gradient $7-35 \% \mathrm{~B}$ for $26 \mathrm{~min}, 35-7 \% \mathrm{~B}$ for $6 \mathrm{~min}$ and $7 \% \mathrm{~B}$ for $3 \mathrm{~min}$.

The solutions used as the mobile phase and the samples were previously filtered through a $0.22-\mu \mathrm{m}$ membrane. The sample volume that was manually injected in both methods was $20 \mu \mathrm{L}$, and the wavelength used for the detection of the flavonols was $370 \mathrm{~nm}$. Both phenolic compounds were quantified through a calibration curve by the injection of standards at different concentrations, expressed in $\mathrm{mg} \mathrm{L}^{-1}$. Subsequently, the percentage of myricetin yield was calculated according to equation 2 :

$\mathrm{Y}(\%)=\left[\frac{\mathrm{C}_{\mathrm{M}} 100}{\mathrm{Ci}_{\mathrm{M} 3 \mathrm{R}} 0.6853}\right]$

where $\mathrm{C}_{\mathrm{M}}$ and $\mathrm{Ci}_{\mathrm{M} 3 \mathrm{R}}$ are the concentrations of myricetin and $\mathrm{M} 3 \mathrm{R}$, respectively. The factor 0.6853 is related to the ratio between the molecular weights of myricetin (318.235 $\left.\mathrm{g} \mathrm{mol}^{-1}\right)$ and M3R (464.379 $\left.\mathrm{g} \mathrm{mol}^{-1}\right)$.

\section{Evaluation of antioxidant capacity}

The TEAC assay used was a method adapted by our team ${ }^{10}$ from the original protocol ${ }^{24}$ to perform an analysis using transparent microplates. The reaction mechanism of this method involves transferring electrons and measuring the scavenging of the radical $\mathrm{ABTS}^{+\bullet} \cdot{ }^{24}$ The analysis was performed in triplicate, and the results are expressed in micromol of Trolox equivalents per liter ( $\left.\mu \mathrm{mol} \mathrm{TE} \mathrm{L}{ }^{-1}\right)$.

\section{Results and Discussion}

\section{Preliminary studies}

Initially, two studies were conducted to determine the type of alcohol (methanol or ethanol) and the percentage of alcohol (v/v) required to solubilize both M3R and its aglycone form, myricetin. In Figure 1, it is observed that both alcohols allow the complete conversion of the flavonol glycoside to aglycone because no peak (retention time $\left(t_{R}\right)=3.8$ min) of M3R could be detected after the elution of the hydrolysates containing methanol or ethanol. Interestingly, a higher amount of myricetin was present when ethanol was used in the reaction.

This behavior is probably because ethanol is more apolar than methanol, thus favoring the solubility of the aglycone produced during the acid treatment. In fact, the results obtained for the solubility of quercetin (another flavonol) in water, water-methanol, and water-ethanol showed that the solubility of quercetin is higher when a water-ethanol mixture is used as the solvent. ${ }^{25}$

Another experiment was conducted to investigate the best percentage of ethanol to solubilize and preserve the myricetin during the reaction (Figure 2). The aglycone concentration increased when the ethanol proportion varied from $20-60 \%$, and the concentration then decreased significantly, probably due to the lack of solubility of both M3R and intermediate form before cleavage. Thus, the percentage of $60 \%$ was established as suitable for hydrolysis.

\section{Optimization of acid hydrolysis by RSM}

To optimize the acid hydrolysis, RSM was used to evaluate the impact of the $\mathrm{HCl}$ concentration $([\mathrm{HCl}])$, reaction time (time) and temperature $(\mathrm{T})$ on the percentage yield of the reaction. Table 2 shows the different experimental conditions and their experimental results of aglycone yield.

The yield values were subjected to an analysis of variance (ANOVA) and lack of fit test on a $2^{\text {nd }}$-order polynomial model. The ANOVA (Table 3 ) showed that the model was statistically significant $(p<0.05)$, indicating that the experimental variation of the response (reaction yield) 


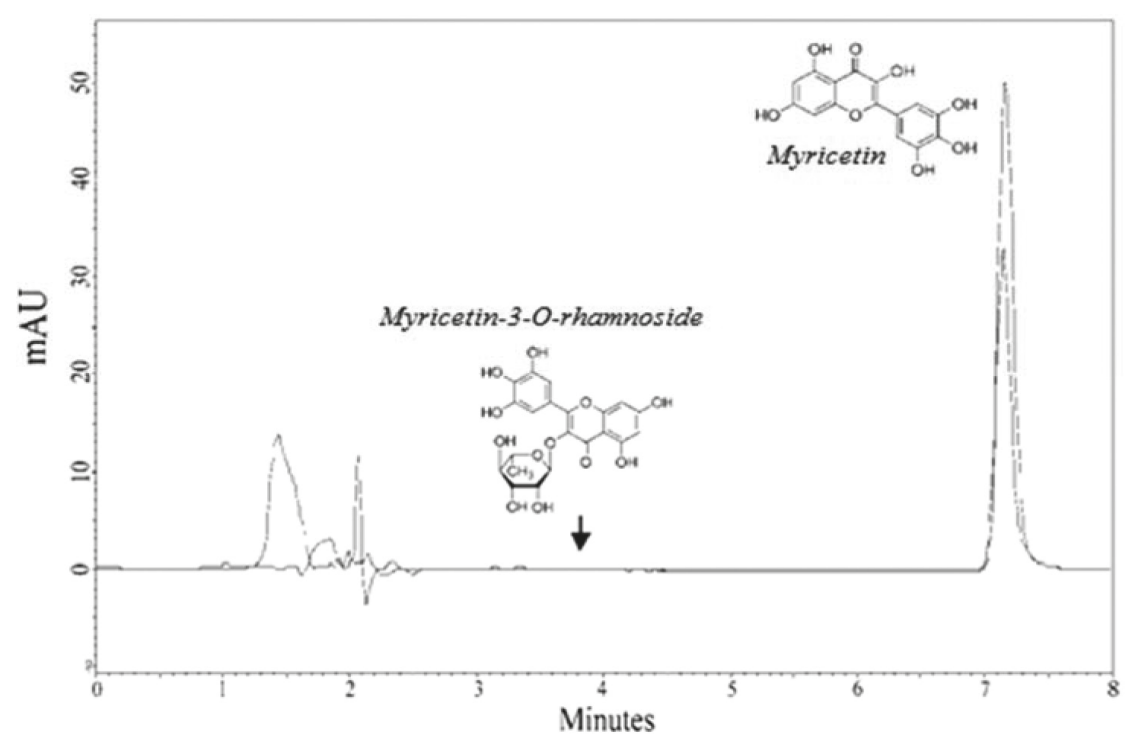

Figure 1. HPLC chromatogram of the acid hydrolysis of myricetin-3- $O$-rhamnoside in hydroalcoholic solutions with $60 \%$ methanol (continuous line) and $60 \%$ ethanol (dotted line) in the reaction medium.

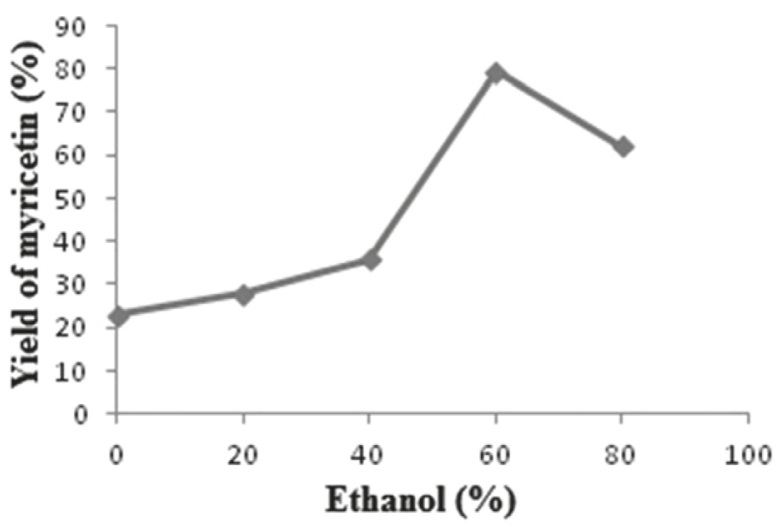

Figure 2. Effect of ethanol:water ratio (v/v) on the concentration of myricetin recovered after the hydrolysis of myricetin-3-O-rhamnoside.

can be explained by at least one of the model parameters. ${ }^{16}$ The lack of fit test was not statistically significant $(p>0.05)$, which indicated that the model proposed for hydrolysis is adequate to fit the observed experimental data. The model achieved a coefficient of determination $\left(\mathrm{R}^{2}\right)$ value of 0.8269 ; i.e., most of the variability in the response can be explained by the model.

The regression coefficients of the $2^{\text {nd }}$-order polynomial model are presented in Table 4 . The results indicate that the yield of myricetin depends strongly on the linear terms of $\mathrm{HCl}$ and $\mathrm{T}$, on the quadratic term of $\mathrm{HCl}$ and on the interactions between $\mathrm{HCl}$ and $\mathrm{T}$. The positive linear coefficient for $\mathrm{HCl}$ indicates that the yield of myricetin globally increases with the concentration of the catalyst, although the negative quadratic effect for $\mathrm{HCl}$ shows that there is a maximum yield, and further increases in the $\mathrm{HCl}$ concentration decrease the yield of the reaction. The presence of acid significantly accelerates the M3R
Table 2. Experimental data obtained during the study on the acid hydrolysis of myricetin-3-O-rhamnoside

\begin{tabular}{|c|c|c|c|c|}
\hline \multirow{2}{*}{ Run } & \multicolumn{3}{|c|}{ Experimental condition } & \multirow{2}{*}{$\frac{\text { Myricetin }}{\text { Yield / \% }}$} \\
\hline & $\mathrm{HCl} / \mathrm{M}$ & $\mathrm{T} /{ }^{\circ} \mathrm{C}$ & time / min & \\
\hline 1 & 1.1 & 60 & 60 & 40.18 \\
\hline 2 & 1.1 & 90 & 180 & 77.34 \\
\hline 3 & 3.9 & 60 & 180 & 85.59 \\
\hline 4 & 3.9 & 90 & 60 & 63.75 \\
\hline 5 & 2.5 & 75 & 120 & 84.93 \\
\hline 6 & 2.5 & 75 & 120 & 82.81 \\
\hline 7 & 1.1 & 60 & 180 & 48.42 \\
\hline 8 & 1.1 & 90 & 60 & 73.75 \\
\hline 9 & 3.9 & 60 & 60 & 88.14 \\
\hline 10 & 3.9 & 90 & 180 & 40.43 \\
\hline 11 & 2.5 & 75 & 120 & 77.66 \\
\hline 12 & 2.5 & 75 & 120 & 77.49 \\
\hline 13 & 0.22 & 75 & 120 & 37.27 \\
\hline 14 & 4.78 & 75 & 120 & 89.52 \\
\hline 15 & 2.5 & 50.5 & 120 & 90.31 \\
\hline 16 & 2.5 & 99.5 & 120 & 59.04 \\
\hline 17 & 2.5 & 75 & 22.2 & 86.11 \\
\hline 18 & 2.5 & 75 & 217.8 & 71.20 \\
\hline 19 & 2.5 & 75 & 120 & 72.40 \\
\hline 20 & 2.5 & 75 & 120 & 85.69 \\
\hline
\end{tabular}

hydrolysis by the protonation of the reaction medium until a maximum point, beyond which the yield decreases, probably due to myricetin degradation. The same behavior was observed by Wang et $a l .{ }^{26}$ when the concentration of 
Table 3. Analysis of variance for the response surface quadratic model of apparent myricetin released after the acid hydrolysis of myricetin3-O-rhamnoside

\begin{tabular}{lcccc}
\hline & $\begin{array}{c}\text { Degrees of } \\
\text { freedom }\end{array}$ & $\begin{array}{c}\text { Sum of } \\
\text { squares }\end{array}$ & $\begin{array}{c}\text { Mean of } \\
\text { squares }\end{array}$ & $F^{\mathrm{a}}$ \\
\hline Model & 9 & 4934.40 & 4934.40 & $146.45^{\mathrm{b}}$ \\
Lack of fit & 5 & 830.48 & 166.09 & $4.93^{\mathrm{c}}$ \\
Pure error & 5 & 168.46 & 33.69 & \\
\hline $\mathrm{R}^{2}$ & \multicolumn{4}{c}{0.8269} \\
\hline
\end{tabular}

${ }^{\mathrm{a}}$ Fisher test; ${ }^{\mathrm{b}}$ significant at $p<0.05$; ${ }^{\mathrm{c}}$ not significant $(p>0.05)$. $\mathrm{R}^{2}$ : coefficient of determination.

Table 4. Parameters estimated for the predicted second-order model for the response variable (apparent myricetin yield)

\begin{tabular}{lcc}
\hline Model parameter & $\begin{array}{c}\text { Coefficient of } \\
\text { regression }\end{array}$ & Standard error \\
\hline Intercept & $80.24^{\mathrm{a}}$ & 2.36 \\
{$[\mathrm{HCl}] / \mathrm{M}$} & $9.26^{\mathrm{b}}$ & 1.59 \\
{$[\mathrm{HCl}]^{2}$} & $-7.68^{\mathrm{b}}$ & 1.60 \\
$\mathrm{~T} /{ }^{\circ} \mathrm{C}$ & $-4.36^{\mathrm{c}}$ & 1.59 \\
$\mathrm{~T}^{2}$ & $-3.46^{\mathrm{d}}$ & 1.60 \\
time $^{\mathrm{b}}$ min & $-2.88^{\mathrm{d}}$ & 1.59 \\
time & \\
{$[\mathrm{HCl}] \times \mathrm{T}$} & $-1.96^{\mathrm{d}}$ & 1.60 \\
{$[\mathrm{HCl}] \times$ time } & $-16.50^{\mathrm{a}}$ & 2.05 \\
$\mathrm{~T} \times$ time & $-4.71^{\mathrm{d}}$ & 2.05 \\
\hline
\end{tabular}

a,b,c, Significant at $p<0.001, p<0.01$ and $p<0.05$, respectively; ${ }^{\mathrm{d}}$ not significant $(p>0.05)$. T: temperature.

phosphoric acid used in the hydrolysis of rutin was higher than $2.5 \%$. This effect might be due to the instability of aglycone at relatively high temperatures in the presence of a strong acid.

The negative effect of temperature was more pronounced when the $\mathrm{HCl}$ concentration was higher, as indicated by the negative interaction term (Table 4). This result clearly suggests that a maximum yield can be achieved at a lower temperature and higher $\mathrm{HCl}$ concentration (Figure 3). This effect could also be observed in the optimization of the acid hydrolysis of soybean isoflavones ${ }^{27}$ and of red wine anthocyanin. ${ }^{28}$

\section{Determination of optimum conditions and model validation}

To verify the validity of the model, optimum conditions were sought using a maximum desirability (D) for the yield. The maximum value found for $\mathrm{D}$ was 0.82 , indicating that the hydrolysis process can be optimized at $2.5 \mathrm{M} \mathrm{HCl}$ and under heating at $75{ }^{\circ} \mathrm{C}$ for $60 \mathrm{~min}$. In

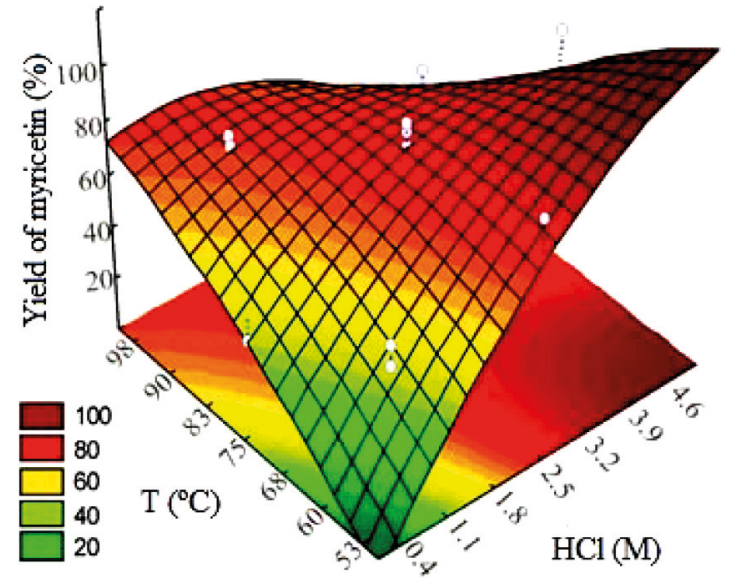

Figure 3. Response surface and contour plot of the yield percentage of myricetin formed after $120 \mathrm{~min}$ of hydrolysis as a function of the interaction between the temperature $(\mathrm{T})$ and concentration of $\mathrm{HCl}$ of the reaction medium.

this condition, the predicted yield is $81.2 \pm 6.68 \%$. After performing three hydrolyses of M3R under these optimal conditions, we observed a yield of $81.15 \pm 9.97 \%$. Similar results were reported for the hydrolysis of the flavones of Flos chrysanthemi extract $(2.4 \mathrm{M} \mathrm{HCl}, 80 \%$ methanol, $80^{\circ} \mathrm{C}$ for $120 \mathrm{~min}$ ) to produce maximum concentrations of luteolin, apigenin and diosmetin. ${ }^{29}$ The optimal conditions found for the hydrolysis of the glycosides of myricetin of Malpighia glabra (cherry) were $0.6 \mathrm{M} \mathrm{HCl}$ and $90{ }^{\circ} \mathrm{C}$ for 40 min..$^{30}$

Application of optimum hydrolysis conditions to purified extract of Inga edulis

We used the optimum experimental conditions for the hydrolysis of the flavonol M3R present in the leaf extract of I. edulis. The effect of hydrolysis was qualitatively evaluated by comparing the chromatographic profiles of the extract before and after hydrolysis, as shown in Figure 4.

In the chromatogram of Figure 4a, there is a large peak of M3R $(370 \mathrm{~nm})$ that, after hydrolysis, was converted into myricetin. Quercetin could also be detected after the treatment (Figure $4 \mathrm{~b}$ ). This aglycone was probably derived from the hydrolysis of the quercetin glycosides that are present in the I. edulis leaf extract. ${ }^{16}$ After hydrolysis, the I. edulis extract had a red color due to the presence of delphinidin and cyanidin (Figure 4b), which are derived from the acid cleavage of the proanthocyanidins present in the extract. ${ }^{10}$

\section{Evaluation of antioxidant capacity}

We evaluated the effect of the optimized acid hydrolysis on the antioxidant capacity of M3R $\left(4567 \pm 189 \mu \mathrm{mol} \mathrm{TE} \mathrm{L} \mathrm{L}^{-1}\right)$ 

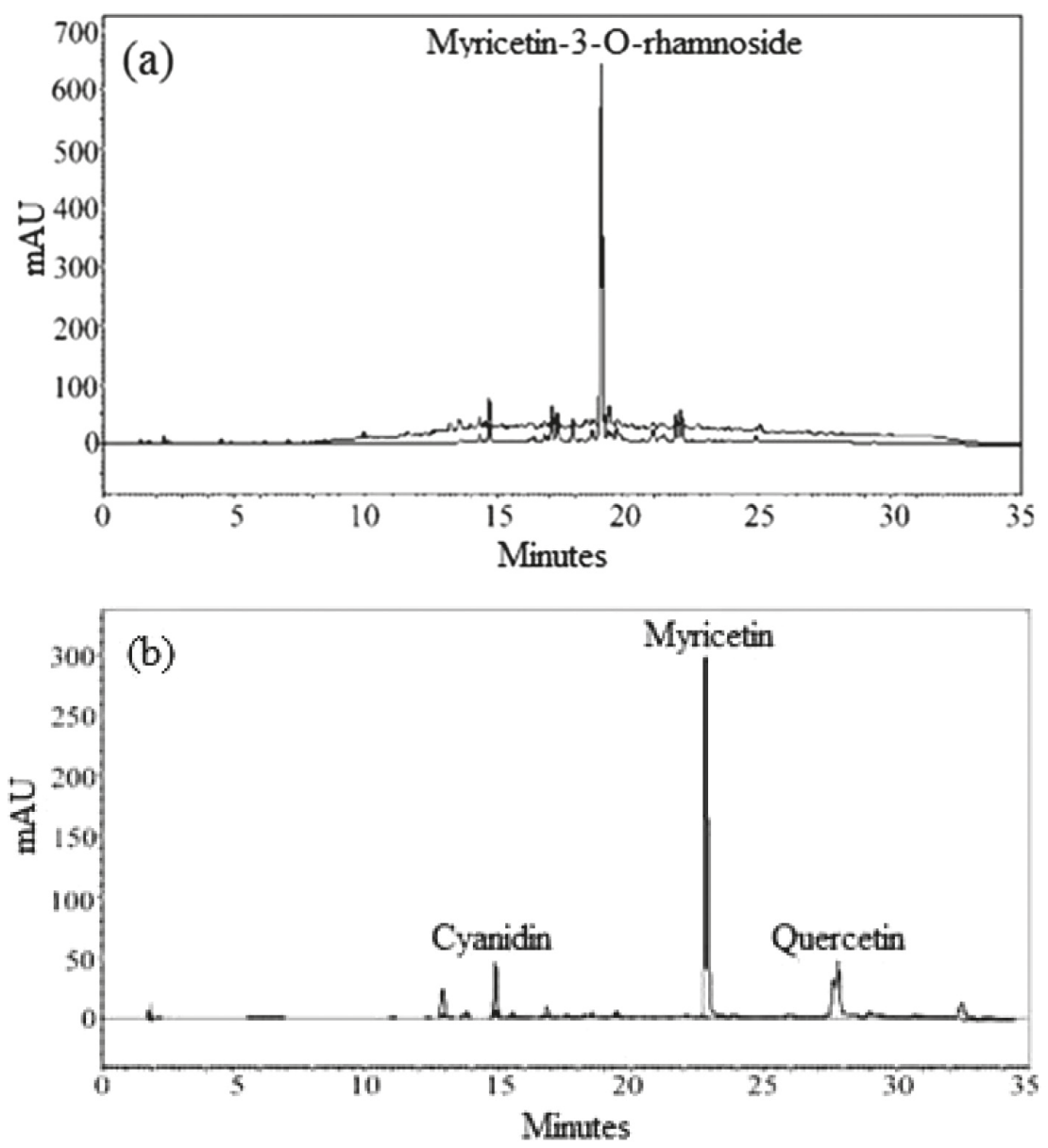

Figure 4. Chromatogram of the extract of Inga edulis leaves before (a) and after (b) acid hydrolysis.

and the extract of $I$. edulis leaf $\left(2345 \pm 142 \mu \mathrm{mol} \mathrm{TE} \mathrm{L}^{-1}\right)$ using the TEAC assay. The TEAC results after the hydrolysis of M3R $\left(5227 \pm 472 \mu \mathrm{mol} \mathrm{TE} \mathrm{L}^{-1}\right)$ and I. edulis extract $\left(2283 \pm 57 \mu \mathrm{mol} \mathrm{TE} \mathrm{L}{ }^{-1}\right)$ showed that the acid treatment had not modified the antioxidant capacity $(p>0.05)$. This result confirms that acid hydrolysis can be employed to reduce the polarity of the phenolic compounds without reducing their antioxidant capacity.

\section{Conclusions}

By using RSM, it is possible to propose an optimized process for the hydrolysis of M3R and to assess the effect of this process on the antioxidant capacity for Trolox equivalent antioxidant capacity assay. The optimum conditions for acid hydrolysis were achieved. Under these conditions, the conversion of glucoside to aglycone presented a yield of $81.15 \%$, thus enabling the conservation of the TEAC antioxidant activity of M3R (now in the form of myricetin) and the extract of I. edulis leaf. This control of the lipophilicity/hydrophilicity balance of naturally occurring antioxidants serves as a good approach to develop novel antioxidants with expanded application in more diverse systems, e.g., fats and oils, lipid-based foods, cosmetic formulas, emulsions and many biological environments.

\section{Acknowledgments}

We acknowledge ARES (Académie de Recherche et d'Enseignement Supérieur, Belgium), FAPESPA (Fundação Amazônia Paraense, Brazil), PROPESP-UFPA (Pró-Reitoria de Pesquisa e Pós-Graduação da UFPA) and $\mathrm{CNPq}$ (Conselho Nacional de Desenvolvimento Científico e Tecnológico, Brazil) for the financial support.

\section{References}

1. Halliwell, B.; Murcia, M. A.; Chirico, S.; Aruoma, O. I.; Crit. Rev. Food Sci. Nutr. 1995, 35, 7.

2. Lobo, V.; Patil, A.; Phatak, A.; Chandra, N.; Pharmacogn. Rev. 2010, 4, 118.

3. Sindhi, V.; Gupta, V.; Sharma, K.; Bhatnagar, S.; Kumari, R.; Dhaka, N.; J. Pharm. Res. 2013, 7, 828. 
4. Brewer, M. S.; Compr. Rev. Food Sci. Food Saf. 2011, 10, 221.

5. Núñez-Sellés, A. J.; J. Braz. Chem. Soc. 2005, 16, 699.

6. Crozier, A.; Jaganath, I. B.; Clifford, M. N. A.; Nat. Prod. Rep. 2009, 26, 965.

7. Michotte, D.; Rogez, H.; Chirinos, R.; Mignolet, E.; Campos, D.; Larondelle, Y.; Food Chem. 2011, 129, 1228.

8. Nichols, J. D.; Carpenter, L.; For. Ecol. Manage. 2006, 233, 344.

9. Souza, J. N. S.; Silva, E. M.; Silva, M. N.; Arruda, M. S. P.; Larondelle, Y.; Rogez, H.; J. Braz. Chem. Soc. 2007, 18, 1276.

10. Dias, A. L. S.; Souza, J. N. S.; Rogez, H.; Quim. Nova 2009, $15,1$.

11. Shahidi, F.; Zhong, Y.; Eur. J. Lipid Sci. Technol. 2010, 112, 930.

12. Pompeu, D. R.; Moura, F. G.; Silva, E. M.; Rogez, H.; Sep. Sci. Technol. 2010, 45, 700.

13. McClements, D. J.; Adv. Colloid Interface Sci. 2015, 219, 27.

14. Parekh, I.; Khanvilkar, A.; Naik, A.; J. Food Process. Preserv. 2017, 41, e13244.

15. Hasnat, M. A.; Pervin, M.; Kim, D. H.; Kim, Y. J.; Lee, J. J.; Pyo, H. J.; Lee, C. W.; Lim, B. O.; Food Sci. Biotechnol. 2015, 24, 689.

16. Mbatia, B.; Shanker, S.; Mattiasson, B.; Mulaa, F.; Adlercreutz, P.; J. Agric. Food Chem. 2011, 59, 7021.

17. Chambi, F.; Chirinos, R.; Pedreschi, R.; Betalleluz-Pallardel, I.; Debaste, F.; Campos, D.; Ind. Crops Prod. 2013, 47, 168.

18. Pereira, D.; Pinheiro, R. S.; Heldt, L. F. S.; de Moura, C.; Bianchin, M.; Almeida, J. F.; dos Reis, A. S.; Ribeiro, I. S.; Haminiuk, C. W. I.; Carpes, S. T.; Food Sci. Technol. 2017, 37, 17.
19. Kim, T. J.; Silva, J. L.; Jung, Y. S.; Food Chem. 2011, 126, 116.

20. Silva, E. M.; Rogez, H.; Larondelle, Y.; Sep. Purif. Technol. 2007, 55, 381.

21. Silva, E. M.; Rogez, H.; da Silva, I. Q.; Larondelle, Y.; Food Bioprod. Process. 2012, 91, 558.

22. Maricán, A.; Ahumada, I.; Richter, P.; J. Braz. Chem. Soc. 2012, 23, 267.

23. Mang, D. Y.; Abdou, A. B.; Njintang, N. Y.; Djiogue, E. J. M.; Loura, B. B.; Mbofung, M. C.; J. Food Meas. Charact. 2015, 9, 495.

24. Re, R.; Pelligrini, N.; Proteggente, A.; Pannala, A.; Yang, M.; Rice-Evans, C. A.; Free Radical Biol. Med. 1999, 26, 1231.

25. Razmara, R. S.; Daneshfar, A.; Sahraei, R.; J. Chem. Eng. Data 2010, 55, 3934.

26. Wang, J.; Zhao, L.; Sun, G.; Liang, Y.; Wu, F.; Chen, Z.; Cui, S.; Afr. J. Biotechnol. 2011, 10, 1460.

27. Chiang, W.; Shih, C.-J.; Chu, Y.-H.; J. Food Chem. 2001, 72, 409.

28. Pinho, C.; Melo, A.; Mansilha, C.; Ferreira, I. M. P. L. V. O.; J. Agric. Food Chem. 2011, 59, 50.

29. Li, F. G.; Zhou, H.; Sun, D. L.; Wang, R. W.; Zeng, S.; Jiang, H. D.; J. Chin. Pharm. Sci. 2009, 18, 55.

30. Ribani, R. H.; Amaya, D. B. R.; Quim. Nova 2008, 31, 1378.

Submitted: December 13, 2017

Published online: June 26, 2018 